\title{
Optimal management of Barrett's esophagus: pharmacologic, endoscopic, and surgical interventions
}

This article was published in the following Dove Press journal:

Therapeutics and Clinical Risk Management

2I November 20II

Number of times this article has been viewed

\author{
Vani JA Konda' \\ Kunal Dalal ${ }^{2}$ \\ 'Section of Gastroenterology, \\ Department of Medicine, \\ ${ }^{2}$ Department of Internal Medicine, \\ University of Chicago Medical Center, \\ Chicago, Illinois, USA
}

\begin{abstract}
Esophageal adenocarcinoma and its precursor, Barrett's esophagus, are rapidly rising in incidence. This review serves to highlight the role of pharmacologic, endoscopic, and surgical intervention in the management of Barrett's esophagus, which requires acid suppression and endoscopic assessment. Treatment with a proton pump inhibitor may decrease acid exposure and delay the progression to dysplasia. Patients who require aspirin for cardioprotection or other indications may also benefit in terms of a protective effect against the development of esophageal cancer. However, without other indications, aspirin is not indicated solely to prevent cancer. A careful endoscopic examination should include assessment of any visible lesions in a Barrett's segment. An expert gastrointestinal pathologist should confirm neoplasia in the setting of Barrett's esophagus. For those patients with high-grade dysplasia or intramucosal carcinoma, careful consideration of endoscopic therapy or surgical therapy must be given. All visible lesions in the setting of dysplasia should be targeted with focal endoscopic mucosal resection for both accurate histopathologic diagnosis and treatment. The remainder of the Barrett's epithelium should be eradicated to address all synchronous and metachronous lesions. This may be done by tissue acquiring or nontissue acquiring means. Radiofrequency ablation has a positive benefit-risk profile for flat Barrett's esophagus. At this time, endoscopic therapy is not indicated for nondysplastic Barrett's esophagus. Esophagectomy is still reserved for selected cases with evidence of lymph node metastasis, unsuccessful endoscopic therapy, or with high-risk features of high-grade dysplasia or intramucosal carcinoma.
\end{abstract}

Keywords: Barrett's esophagus, high-grade dysplasia, esophagectomy, ablation, endoscopic mucosal resection

\section{Introduction}

The incidence of esophageal adenocarcinoma has risen dramatically over the last 30 years. ${ }^{1}$ The mortality rate from esophageal adenocarcinoma is dismal, with 5-year survival rates for advanced-stage adenocarcinoma being $<15 \%$. $^{2}$ The presence of Barrett's metaplasia is the single most important risk factor for esophageal adenocarcinoma, with a 30 -fold increase in risk over the general population. ${ }^{3}$ Acid reflux is believed to play a critical role in the development of Barrett's esophagus. The progression to esophageal adenocarcinoma is based on the sequence of changes from normal squamous epithelium to Barrett's esophagus to dysplasia to cancer. The rate of progression from nondysplastic Barrett's esophagus to esophageal adenocarcinoma is approximately $0.5 \%$ per year. ${ }^{4}$ The key to prevention and early treatment of esophageal adenocarcinoma is the detection and eradication of dysplasia found in Barrett's epithelium. High-grade dysplasia is currently the best marker to identify which patients 
are at risk of progressing to esophageal adenocarcinoma. This review serves to highlight the role of pharmacologic, endoscopic, and surgical intervention in the management of Barrett's esophagus.

Barrett's esophagus is diagnosed by both endoscopy and histology. On endoscopy, it is suspected by the presence of salmon-colored columnar mucosa appearing in the esophagus. These areas should be biopsied, which is necessary to identify specialized intestinal metaplasia, which is a histopathologic diagnosis, widely defined by the presence of goblet cells on biopsy. Dysplasia is defined as cytologic and architectural atypia without evidence of invasion past the basement membrane. The distinction between low-grade dysplasia and high-grade dysplasia is based on the severity of atypia and suggestion of neoplastic transformation. Intramucosal carcinoma refers to tumor that has invaded past the basement membrane but is superficial to the lamina propria. Submucosal carcinoma histologically invades past the muscularis mucosa into the submucosa, but does not extend into the muscularis propria. Distinguishing the various stages of progression to cancer as intestinal metaplasia, low-grade dysplasia, high-grade dysplasia, intramucosal carcinoma, and submucosal carcinoma is crucial in guiding therapeutic intervention.

\section{Medical therapy \\ PPI and H2RA: regression of Barrett's esophagus}

Use of the antisecretory medications, proton pump inhibitors (PPIs) and histamine receptor antagonists (H2RAs), has offered hope of achieving reversal of the metaplastic epithelium characteristics of Barrett's esophagus. Several observational and prospective studies have assessed for regression of Barrett's esophagus in response to PPIs. Studies have defined regression as reduction in overall length of the metaplastic segment in the distal esophagus. Partial regression has been demonstrated by appearance of islands of squamous epithelium within the metaplastic columnar lining. It has been surmised that a reduction in the surface area of Barrett's esophagus would lower the risk of cancer. Studies evaluating regression of Barrett's esophagus have yielded inconsistent results. In studies of patients treated with $\mathrm{H} 2$ blockers, significant regression of Barrett's esophagus was not noted. ${ }^{5-7}$ Thus, acid suppression with H2RA has not proved effective in inducing regression in Barrett's esophagus.

Since the inception of the PPIs in 1989, most studies on Barrett's esophagus have focused on these agents. Several studies have suggested partial regression, as evidenced by appearance or enlargement of squamous islands. Upwards of half of patients on PPI therapy have demonstrated development of new squamous islands or increasing number and size of islands. ${ }^{6,8-11}$ The significance of squamous islands remains unclear because metaplasia may still underlie the islands, and the relatively modest reduction in surface area of Barrett's esophagus at the sites of squamous islands may not decrease the overall risk of cancer in any significant way. Studies of PPI therapy have yielded conflicting data with respect to reduction in length of Barrett's esophagus. Although some studies have demonstrated a decrease length in the Barrett's segment, ${ }^{7,11,12}$ other studies have not demonstrated the same results, including some with high-dose PPIs. ${ }^{10,13,14}$

The incidence of complete regression in response to PPIs has been reported as approximately $2.4 \%{ }^{15}$ in studies generally including only long-segment Barrett's esophagus and reported as $7.1 \%$ in a study including short-segment Barrett's esophagus. ${ }^{16}$ A small number of prospective studies have assessed if normalization of acid exposure leads to regression. Based on a limited number of studies, it appears that control of esophageal $\mathrm{pH}$ by PPIs may be associated with regression of Barrett's esophagus, although control of $\mathrm{pH}$ alone may not be sufficient to cause significant regression. ${ }^{12,14}$

\section{PPI and H2RA: progression to dysplasia and esophageal adenocarcinoma}

Studies suggest that acid reflux plays a key role in the progression to dysplasia and esophageal adenocarcinoma, although this role in malignant progression is unclear. When compared with H2RA, PPI therapy has been shown to be more efficacious in preventing the progression of Barrett's esophagus to both dysplasia and esophageal adenocarcinoma. ${ }^{17,18}$

In observational studies, PPI therapy has been shown to be associated with a lower risk of developing low-grade dysplasia, high-grade dysplasia, and esophageal adenocarcinoma. A study by El Serag et al found the incidence of any grade dysplasia to be significantly lower amongst those receiving PPIs after a diagnosis of Barrett's esophagus compared with those not treated by PPIs. ${ }^{18}$ When considering incidence of high-grade dysplasia or esophageal adenocarcinoma specifically, Nguyen et al demonstrated a lower incidence amongst patients being prescribed versus not being prescribed a PPI (7.4\% versus $14.1 \%) .{ }^{19}$ It is unclear where in the metaplasiadysplasia-esophageal adenocarcinoma sequence that PPIs may exert their greatest effect, but there is some evidence that PPIs may delay progression from metaplasia to dysplasia. Studies suggest that initiating PPI therapy soon after the diagnosis of Barrett's esophagus may prevent this progression. ${ }^{18,20}$ 


\section{NSAIDS and aspirin}

Nonsteroidal anti-inflammatory drug (NSAID) and aspirin use has previously been associated with a decreased risk of developing colon adenocarcinoma, ${ }^{21,22}$ and there has been interest in their role in preventing progression of Barrett's esophagus. NSAIDs and aspirin exert their effects via inhibition of COX-1 and COX-2 enzymes. COX-2 enzyme activity contributes to cancer growth in several ways, such as inhibition of apoptosis and stimulation of angiogenesis. ${ }^{23}$ COX-2 inhibition has been shown to suppress cell growth and increase apoptosis in Barrett's esophagus-associated esophageal adenocarcinoma cell lines. ${ }^{24}$ Overexpression of COX-2 has been demonstrated in patients with reflux esophagitis, Barrett's esophagus, dysplasia, and esophageal adenocarcinoma. ${ }^{25,26}$

A study by Vaughan et al showed that current NSAID (including aspirin) users had an $80 \%$ reduced risk of esophageal adenocarcinoma compared with never-users of NSAIDs, with the 5-year incidence of esophageal adenocarcinoma being $6.6 \%$ versus $14.3 \%$ in current versus never-users. ${ }^{27}$ Additionally, a review of nine studies found a protective association between NSAIDs/aspirin use and esophageal adenocarcinoma, and showed that patients with exposure to NSAIDs or aspirin had a $33 \%$ odds reduction of developing esophageal adenocarcinoma. ${ }^{22}$ Thus, multiple studies demonstrate a protective association between NSAID/aspirin use and development of esophageal adenocarcinoma.

NSAID/aspirin may protect against esophageal adenocarcinoma either by preventing development of Barrett's esophagus or by preventing progression from Barrett's esophagus to esophageal adenocarcinoma. In a retrospective study, NSAID use was not found to be higher in Barrett's esophagus patients versus esophageal adenocarcinoma patients. However, aspirin and NSAID use was lower in both of these groups compared with controls without Barrett's esophagus. If there is a true protective effect of NSAIDs, this study suggests it may occur prior to the development of Barrett's esophagus. ${ }^{28}$

PPI use is widespread in patients with reflux, and thus associations of NSAID use and malignant progression are often in the setting of concomitant PPI use. In one study of patients with at least one filled NSAID/aspirin prescription, the majority of whom also had at least one filled PPI prescription, a reduced risk of esophageal adenocarcinoma was demonstrated.$^{29}$ It is possible that a protective effect is due to a combined effect of each medication.

The findings of the majority of these studies are largely associations and observations, because there are significant barriers in conducting a large clinical trial evaluating
NSAIDs/aspirin as potential chemoprotective agents. At this time, it is the position of the American Gastroenterological Association to advise against using aspirin solely to prevent esophageal adenocarcinoma in the absence of other cardiovascular indications. ${ }^{30}$

\section{Celecoxib}

COX-1 is responsible for maintaining the integrity of the gastrointestinal mucosa, and COX-1 inhibition is associated with an increased incidence of upper gastrointestinal complications, such as peptic ulcer disease. ${ }^{31}$ Thus, selective inhibition of COX-2 by celecoxib may be of benefit with fewer side effects. The Chemoprevention for Barrett's Esophagus Trial, a Phase IIB, multicenter, randomized trial of celecoxib in patients with Barrett's esophagus and lowgrade dysplasia or high-grade dysplasia, randomly assigned 222 patients to treatment with celecoxib or placebo. After 48 weeks, no significant difference was observed in the proportional change of biopsy samples with dysplasia or cancer between the groups. ${ }^{32}$ This trial does not suggest that celecoxib prevents progression of Barrett's esophagus, although further studies are needed.

\section{Endoscopic surveillance and detection of neoplasia}

Routine surveillance of Barrett's esophagus is paramount in early detection of neoplasm and institution of appropriate therapies. Standard surveillance protocols call for four quadrant biopsies performed at every $1-2 \mathrm{~cm}$ intervals from the proximal gastroesophageal junction extending to the squamocolumnar junction. Guidelines proposed by the American College of Gastroenterology provide intervals for surveillance depending on the pathology. ${ }^{33}$ If no dysplasia is detected, a second esophagogastroduodenoscopy with biopsies should be performed within a year, and then at 3-yearly intervals. If lowgrade dysplasia is found, a repeat esophagogastroduodenoscopy with biopsies should be performed within 6 months, and then at 1-yearly intervals until no dysplasia is found on two consecutive esophagogastroduodenoscopies. In the case of high-grade dysplasia, repeat esophagogastroduodenoscopy with four quadrant biopsies at $1 \mathrm{~cm}$ intervals should be performed within 3 months, and then at regular 3-monthly intervals to monitor for esophageal adenocarcinoma if no therapy is performed. Any mucosal irregularity warrants endoscopic mucosal resection. All dysplastic lesions should be confirmed by an expert gastrointestinal pathologist.

The Prague C and M criteria, first introduced in 2004, provide a standardized, validated, and reliable classification 


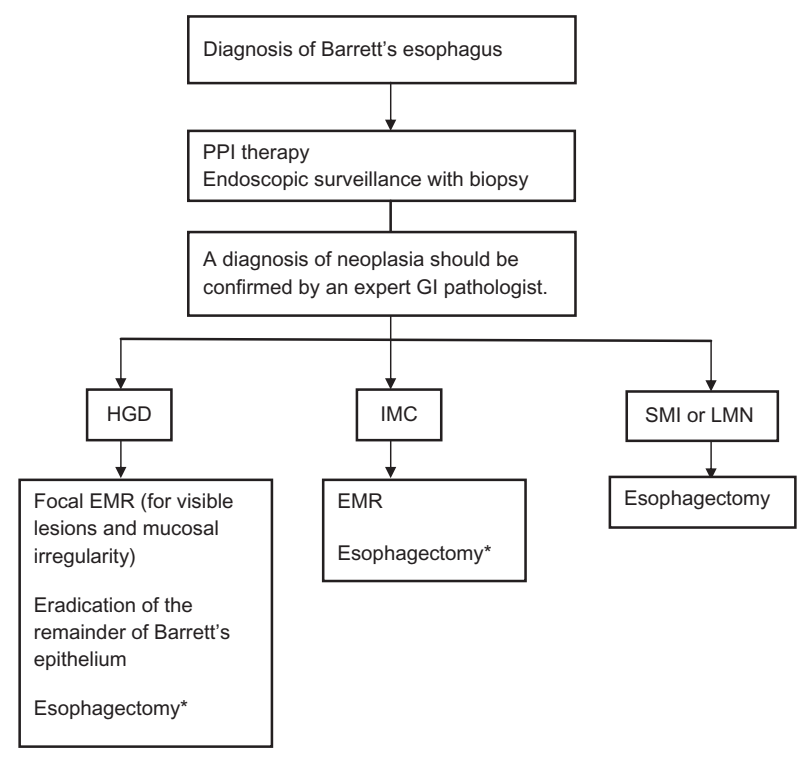

Figure I Management of patients with Barrett's esophagus with neoplasia. ${ }^{34}$

Note: *For high risk cases, ie, HGD from multiple levels, poorly differentiated tumor, invasion of lymphatics, blood vessels, or neural structures.

Abbreviations: EMR, endoscopic mucosal resection; GI, gastrointestinal; PPI, proton pump inhibitor; HGD, high-grade dysplasia; IMC, intramucosal carcinoma; SMI, submucosal invasion; LNM, lymph node metastasis.

system for the endoscopic description of Barrett's esophagus. ${ }^{35}$ The key steps involve: identifying the gastroesophageal junction by recognizing key landmarks, such as the proximal margin of the gastric mucosal folds, pinch at the distal esophagus, and diaphragmatic hiatus; defining the proximal extent of circumferential columnar-appearing mucosa in centimeters above the gastroesophageal junction and reporting this distance as the $\mathrm{C}$ value, defining the maximum extent of any tongues of columnar-appearing mucosa above the gastroesophageal junction and reporting this distance as the $\mathrm{M}$ value.

Surveillance protocols utilizing white light examination have been essential in recognition of lesions, but dysplastic lesions are still often missed on biopsy. A detailed examination of the Barrett's segment with high-resolution white light endoscopy is critical in the assessment for neoplasia. Additional imaging modalities may offer improved mucosal visualization and assessment of structural changes, thereby allowing for identification of abnormal areas and appropriately targeting biopsies. Narrow band imaging is a technique that utilizes narrowed bandwidths of blue and green light to improve visibility of microstructural and capillary patterns in Barrett's esophagus, without using dyes. Shorter wavelength light has superficial penetration, and is ideal for mucosal imaging. Narrow band imaging with magnification has been shown to have high sensitivity for diagnosing intestinal metaplasia and high-grade dysplasia on the basis of irregular mucosal pit patterns or irregular microvasculature, but poor specificity. ${ }^{36}$ Clinically, this may reduce the need for multiple random biopsies and increase the histologic yield of dysplasia. However, addition of narrow band imaging to high-resolution white light endoscopy has not been shown to improve interobserver agreement or increase yield in identifying early neoplasia. ${ }^{37}$

Additional techniques are being studied and utilized at high-volume centers. Autofluorescence imaging uses endogenous tissue substances (fluorophores), which become excited by light and emit light of longer wavelength than the exciting light. With autofluorescence imaging, normal esophagus and nondysplastic Barrett's esophagus appears green, whereas areas of highgrade dysplasia/adenocarcinoma appear blue or violet. However, it is associated with a high false-positive rate. ${ }^{38}$ Confocal laser microendoscopy allows for targeting of suspicious areas for biopsy and real-time histologic assessment of the epithelium. Both the epithelium and subepithelial vascular structures can be imaged at various depths, ${ }^{39}$ and confocal laser microendoscopy has been shown to increase diagnostic yield of endoscopically inapparent neoplastic epithelium significantly compared with standard endoscopy. ${ }^{40}$ Finally, in chromoendoscopy, a chemical agent such as methylene blue, indigo carmine, or acetic acid is applied to the esophageal mucosa to distinguish epithelial subtypes based on different pit patterns.

Although the gold standard for diagnosis is histology, there exists high interinterpreter variability in diagnosing dysplasia. ${ }^{41-43}$ Inherent to the challenge in diagnosing dysplasia is that neoplastic transformation represents a biologic and histologic continuum, but the pathologist must discretely categorize lesions as Barrett's esophagus, low-grade dysplasia, high-grade dysplasia, intramucosal carcinoma, or submucosal carcinoma. Cytologic features of dysplasia may be confused with inflammatory changes, and often limitations in sample size, depth, and potential crush artifact make it difficult to distinguish reliably between various stages of disease based on a single biopsy specimen. Prior to embarking on any therapy for Barrett's associated neoplasia, the dysplasia should be confirmed by an expert gastrointestinal pathologist.

Furthermore, endoscopic evaluation should include specific attention to any visible lesions. Rigorous assessment of the remainder of the Barrett's epithelium should be done to evaluate for any occult neoplasia. Visible lesions, including mucosal irregularities, in the setting of dysplasia should be targeted with endoscopic mucosal resection for accurate 
histopathologic staging. Larger and more intact specimens from endoscopic resection may allow pathologists to make a more reliable staging diagnosis. The effect of staging by endoscopic mucosal resection specimens is demonstrated by our center's complete Barrett's eradication endoscopic mucosal resection study, which upstaged seven of 49 (14\%) and downstaged 15 of 49 (31\%) cases by endoscopic mucosal resection compared with pretreatment endoscopic biopsies. ${ }^{44}$ Additionally, in a large study comparing Barrett's esophagus patients undergoing endoscopic mucosal resection versus biopsy, significantly greater interobserver agreement on the diagnosis of dysplasia was demonstrated for endoscopic mucosal resection specimens. ${ }^{45}$

\section{Endoscopic therapy}

Endoscopic therapy is now an established form of treatment at referral centers for neoplasia associated with Barrett's esophagus. These modalities offer an organ-sparing and safer approach compared with esophagectomy, and patients with high-grade dysplasia or intramucosal carcinoma may be appropriate candidates for treatment (see Figure 1). Endoscopic therapy does not confer the same benefit for low-grade dysplasia or nondysplastic Barrett's esophagus, given the potential complications of therapy and the lower risk of malignant transformation in these patients. Future risk stratification may enable us to select which patients may benefit from intervention in these populations.

The risk of Barrett's esophagus patients with high-grade dysplasia harboring occult invasive esophageal adenocarcinoma is estimated at around $40 \%,{ }^{46}$ and this has previously supported prophylactic esophagectomy over endoscopic monitoring. A review of the literature reporting rates of invasive cancer in 441 patients who underwent prophylactic esophagectomy for high-grade dysplasia demonstrated a pooled average rate of $39.9 \%$. This rate was decreased to $12.7 \%$ when applying the strict definition of invasive cancer as being tumor invading the submucosa, and most patients were actually found to have intramucosal carcinoma. ${ }^{47}$ Intramucosal carcinoma carries a $\leq 3 \%$ risk of nodal metastasis, ${ }^{47-51}$ and thus may be amenable to local endoscopic treatment. ${ }^{44,52}$ By comparison, submucosal invasion carries a higher risk of nodal metastasis, thus surgery and/or systemic therapy is required. ${ }^{48,53}$ With accurate distinction between high-grade dysplasia and intramucosal carcinoma from invasive cancer, endoscopic therapy may instead be a more appropriate alternative than esophagectomy.

Endoscopic therapy for high-grade dysplasia or intramucosal carcinoma is performed with the goal of preserving the esophagus while ablating all Barrett's esophagus epithelium to prevent neoplastic progression. This includes ablating both dysplastic and nondysplastic epithelium due to the risk of developing synchronous or metachronous lesions in remaining metaplastic Barrett's esophagus tissue. ${ }^{54}$ Endoscopic therapies include tissue acquiring and nontissue acquiring modalities. Endoscopic resection, including both endoscopic mucosal resection and endoscopic mucosal dissection is a tissue-acquiring modality, and allows for histopathologic diagnosis. Nontissue acquiring modalities include photodynamic therapy, radiofrequency ablation, and cryotherapy, which treat by tissue destruction.

\section{Endoscopic resection}

Endoscopic mucosal resection and endoscopic mucosal dissection allow for removal of tissue and establishing a histopathologic diagnosis. Endoscopic mucosal resection can be performed using the band ligation or cap technique, both of which involve endoscopic suction with a friction fitted cap to create a pseudopolyp. Endoscopic mucosal resection can be performed focally or for the entirety of the Barrett's epithelium. Focal endoscopic mucosal resection can be performed on suspicious-appearing lesions, but is associated with high recurrence rates, ranging from $14 \%-47 \%$ in the studies. ${ }^{55-62}$ These high rates are due in part to multifocal synchronous lesions previously missed by biopsy, as well as the metachronous development of new lesions. ${ }^{63}$ Five-year follow-up data for 231 Barrett's esophagus patients with intramucosal carcinoma demonstrated a $95.7 \%$ complete response rate in one study. ${ }^{64}$

Complete Barrett's eradication endoscopic mucosal resection also known as circumferential endoscopic mucosal resection, stepwise radical endoscopic resection, or wide area endoscopic mucosal resection, involves resecting the entire Barrett's segment. This minimizes the risk of potential development of synchronous or metachronous lesions. Complete response from complete Barrett's eradication endoscopic mucosal resection has been in the range of $76 \%-100 \%$ in studies. ${ }^{44,52,65-67}$ In a multicenter European cohort study, 169 Barrett's esophagus patients with high-grade dysplasia or early carcinoma underwent complete endoscopic mucosal resection. After 27 months of follow-up, remission of neoplasia was demonstrated in $97.5 \%$ of patients, and complete elimination of metaplasia in $85 \%$. The recurrence rate for metachronous lesions was $1.8 \%{ }^{67}$

Endoscopic submucosal dissection involves marking the boundary of a lesion with cautery, injecting a viscous fluid into the submucosal space to provide a cushion under the lesion, 
followed by dissection using a cutting device. ${ }^{68}$ Endoscopic mucosal dissection is utilized for suspicious-appearing lesions larger than $1.5 \mathrm{~cm}$, and employs an en bloc dissection. This approach may be considered for lesions at the gastroesophageal junction or gastric cardia, where it is often difficult to create a pseudopolyp..$^{63}$ The recurrence rate was $0 \%$ in one study of 15 Barrett's esophagus patients who underwent endoscopic mucosal dissection at the gastroesophageal junction for esophageal adenocarcinoma. ${ }^{69}$ One potential barrier to this approach is reflux-induced submucosal fibrosis in the distal esophagus. ${ }^{63}$ Complications of endoscopic mucosal resection include stricture formation in nearly half of cases, bleeding, and rarely, perforation. ${ }^{44,52,65-67,70}$ However, stenoses and bleeding are complications that can be endoscopically treated.

\section{Radiofrequency ablation}

Radiofrequency ablation of a Barrett's esophagus segment can be done circumferentially using a balloon-based catheter or locally using a focal device. Lesions are treated by application of direct thermal energy with electrodes embedded in the circumferential balloon or focal device. There are two separate applications of thermal energy, with scraping of treated tissue between the first and second ablation to ensure adequate and uniform thermal contact. Potential complications of radiofrequency ablation include noncardiac chest pain, nontransmural lacerations, and stricture formation. ${ }^{44}$

Nondysplastic Barrett's esophagus has demonstrated regression in response to radiofrequency ablation in large clinical studies. In the Ablation of Intestinal Metaplasia (AIM) study, a 70\% complete remission rate of Barrett's metaplasia was demonstrated in the circumferentially treated group at 1-year follow-up. Stricture formation did not occur, and no buried Barrett's esophagus was found in the 4306 biopsy specimens. ${ }^{71}$ The AIM-II trial at 2.5-year follow-up demonstrated complete eradication in $98.4 \%$ of patients treated with circumferential radiofrequency ablation followed by focal radiofrequency ablation of remaining Barrett's esophagus. ${ }^{72}$ Five-year outcomes from the AIM-II trial demonstrated complete remission in $92 \%$ of the participating patients, with no buried glands, dysplasia, strictures, or serious adverse events reported. ${ }^{73}$

Radiofrequency ablation has been shown to be efficacious in the treatment of dysplastic Barrett's esophagus as well. In a recent landmark randomized trial, patients with high-grade dysplasia demonstrated complete eradication in $81.0 \%$ of cases treated with radiofrequency ablation compared with $19.0 \%$ in controls. Overall, $77.4 \%$ of patients in the ablation group demonstrated complete eradication of intestinal metaplasia, compared with $2.3 \%$ in controls. Disease progression was lower in the ablation group $(3.6 \%$ versus $16.3 \%$ ) and fewer cancers were noted (1.2\% versus $9.3 \%$ ). The rate of esophageal stricture in the radiofrequency ablation group was $6 \%$, which is much lower than the rate associated with endoscopic mucosal resection. ${ }^{74}$ Similarly, 1-year follow-up in another study of 142 patients with highgrade dysplasia demonstrated a remission rate of $90.2 \% .^{75}$

The efficacy of utilizing both endoscopic mucosal resection and radiofrequency ablation in patients with dysplastic Barrett's esophagus has been evaluated. In a multicenter European trial of 24 patients with Barrett's esophagus, visible lesions were endoscopically resected, followed by serial radiofrequency ablation. Neoplasia and metaplasia was eradicated in $95 \%$ and $88 \%$ of cases, respectively, and recurrence of neoplasia after 22 months of median follow-up was $0 \%{ }^{76}$ Efficacy of focal endoscopic mucosal resection followed by radiofrequency ablation was also demonstrated in a trial of patients with longer Barrett's esophagus segments $(>10 \mathrm{~cm})$, with complete response rates of $83 \%$ and $79 \%$ for neoplasia and intestinal metaplasia, respectively, and no recurrence of neoplasia during 9.1 months of mean follow-up.

The above studies each evaluated the efficacy of focal endoscopic mucosal resection followed by radiofrequency ablation. Whether this approach or stepwise radical endoscopic resection alone is more efficacious and has fewer complications was evaluated by van Vilsteren et al in a randomized trial. Patients in the stepwise radical endoscopic resection group underwent focal endoscopic mucosal resection followed by serial endoscopic mucosal resection, whereas patients in the endoscopic mucosal resection/ radiofrequency ablation group underwent focal endoscopic mucosal resection followed by radiofrequency ablation. Rates of complete remission were similar between the groups (100\% for stepwise radical endoscopic resection versus $96 \%$ for endoscopic mucosal resection/radiofrequency ablation). However, the stepwise radical endoscopic resection group had a much higher rate of stenosis ( $88 \%$ ) and required more endoscopic dilations. ${ }^{70}$

\section{Photodynamic therapy}

Photodynamic therapy employs a light-sensitizing reaction to produce oxygen radicals, which destroy targeted cells. A photosensitizer such as porfimer sodium or 5-aminolevulinic acid is administered intravenously 48-72 hours prior to endoscopy and accumulates in esophageal tissue prior to light activation. Subsequently, a bare cylinder, or balloon-based diffusing light fibers, are introduced endoscopically into the 
esophagus, and activation of the photosensitizer occurs in the dysplastic cells. Free oxygen radicals are generated which eventually induce cellular apoptosis. ${ }^{77}$

Studies suggest that photodynamic therapy is an effective treatment modality for eradication of Barrett's esophagus with high-grade dysplasia and intramucosal carcinoma. Overholt et al retrospectively evaluated 103 patients with low-grade dysplasia, high-grade dysplasia, and intramucosal carcinoma, and intention-to-treat success rates were $92.9 \%$, $77.5 \%$, and $44.4 \%$ for each respective group after a mean of 50 months. Stricture formation overall occurred in $30 \%$ of cases. ${ }^{78}$ Pech et al prospectively followed 66 patients with high-grade dysplasia or intramucosal carcinoma treated with 5-aminolevulinic acid photodynamic therapy and followed for a median of 37 months. Complete response was demonstrated in $97 \%$ of the high-grade dysplasia group and $100 \%$ of the intramucosal carcinoma group. ${ }^{79}$

Limitations of photodynamic therapy include additional time required to administer photosensitizers $2-3$ days prior to therapy. Given the systemic distribution of the photosensitizers, patients must also avoid direct sunlight up to 6 weeks due to potential photosensitivity reactions. ${ }^{77}$ Other adverse effects include noncardiac chest pain and symptomatic stricture formation. Stricture formation was reported in one study to occur in $27 \%$ of patients, with significant risk factors being endoscopic mucosal resection therapy before photodynamic therapy, a prior history of an esophageal stricture, and the number of photodynamic therapy applications. ${ }^{80}$ Another concern is the potential development of subsquamous Barrett's esophagus glands, because cases of esophageal adenocarcinoma arising from such glands after photodynamic therapy have been reported. ${ }^{78,81}$ Given these limitations, photodynamic therapy has fallen out of favor in recent years, and referral centers have adopted endoscopic mucosal resection and radiofrequency ablation as the preferred endoscopic treatment modalities for Barrett's esophagus.

\section{Cryotherapy}

The latest endoscopic treatment modality is cryotherapy, which utilizes a spray catheter introduced via the endoscope and directed at targeted abnormal tissue. Sprayed liquid nitrogen or carbon dioxide is applied, which produces freezethaw cycles that result in tissue destruction by intracellular disruption or tissue ischemia, while minimizing fibrosis. ${ }^{82}$ Orogastric decompression tube placement allows for expulsion of excess gas and prevention of inadvertent perforation. Dumot et al enrolled patients with Barrett's esophagus and high-grade dysplasia or intramucosal carcinoma who were deemed inoperable or had refused esophagectomy into a trial. Thirty patients underwent cryotherapy, and afterwards $27(90 \%)$ demonstrated pathologic downstaging. After 1-year median follow-up, elimination of cancer or downstaging of dysplasia was demonstrated in $68 \%$ of high-grade dysplasia and $80 \%$ of intramucosal carcinoma patients. ${ }^{83}$ In a more recent trial, patients with high-grade dysplasia ( $n=17$ ) demonstrated a 94\% regression rate while patients with intramucosal carcinoma $(n=4)$ and early esophageal adenocarcinoma $(\mathrm{n}=3)$ demonstrated a $100 \%$ regression rate. Complete response to intestinal metaplasia occurred in 53\% with high-grade dysplasia, 75\% with intramucosal carcinoma, and $67 \%$ with esophageal adenocarcinoma. ${ }^{84}$ In a third study of 60 patients with high-grade dysplasia, $97 \%$ had complete eradication of high-grade dysplasia, $87 \%$ had complete eradication of all dysplasia with persistent metaplasia, and $57 \%$ had complete eradication of all metaplasia. ${ }^{85}$

The safety profile of cryotherapy appears to be favorable. From the above series, the overall incidence of stricture formation was $9 / 114$ patients $(7.9 \%),{ }^{83-85}$ which is lower than the reported rates for endoscopic mucosal resection and photodynamic therapy. Perforation occurred in a patient with Marfan syndrome. Other less serious adverse effects included chest pain, dysphagia, odynophagia, and sore throat. ${ }^{84}$ While cryotherapy appears safe, well tolerated, and efficacious for the treatment of high-grade dysplasia and intramucosal carcinoma in Barrett's esophagus, there are no randomized trials comparing it with other modalities. Furthermore, unlike the long-term complete response rates demonstrated for endoscopic mucosal resection, data on long-term efficacy of cryotherapy is lacking.

\section{Post-therapy surveillance}

Current clinical practice requires lifelong surveillance with periodic histologic sampling of eradicated Barrett's esophagus to monitor for recurrence, the presence of buried (subsquamous) glands/metaplasia, and progression to neoplasia. As mentioned, photodynamic therapy has been associated with subsquamous Barrett's esophagus glands that possess neoplastic potential, ${ }^{78-81}$ thus necessitating sufficient depth of biopsy specimens to assess for this risk. Recent studies suggest that biopsy specimens are adequate to assess for buried glands and intestinal metaplasia. Secondary analysis of the AIM dysplasia trial looked at 5648 biopsy specimens from 113 patients who underwent radiofrequency ablation or sham procedures. Biopsy specimens demonstrated a similar rate of subepithelium between both groups (78.4\% for radiofrequency ablation group versus $79.1 \%$ for sham group). ${ }^{86}$ Follow-up of the AIM-II trial 
demonstrated that biopsies at 5 years revealed focal metaplasia in $8 \%$ of patients, demonstrating the importance of surveillance in identifying persistent or recurrent disease.

\section{Surgical management Esophagectomy}

Until the past decade, esophagectomy for Barrett's esophagus with high-grade dysplasia and intramucosal carcinoma had been the traditional standard. Surgery allows for accurate staging and assessment of adequacy by looking for negative margins and lymph nodes. Complete resection of the entire Barrett's segment is done in cases of unsuspected multifocal disease and to minimize the risk of metachronous lesion development in residual Barrett's. ${ }^{87}$ Recently, there has been a shift to treating high-grade dysplasia and intramucosal carcinoma with endoscopic therapies, but submucosal invasion remains an indication for esophagectomy. Esophagectomy is still reserved for select cases with evidence of lymph node metastasis, unsuccessful endoscopic therapy, or with high-risk features of high-grade dysplasia or intramucosal carcinoma. ${ }^{88}$ High-risk features to consider include highgrade dysplasia obtained from multiple levels, protruding or excavated lesions, poorly differentiated tumors, and invasion into lymphatic channels, blood vessels, or neural structures. ${ }^{88}$ A patient's age, comorbidities, and willingness to undergo surgery should also be taken into account.

Compared with endoscopic treatment, there is significant morbidity and mortality associated with esophagectomy, with overall morbidity rates as high as $50 \%$ and mortality as high as $10 \%{ }^{89}$ Adverse outcomes include pulmonary complications, hemorrhage, anastomotic leak, infection, postoperative arrythmias, and nerve palsy. When considering the mortality rates for esophagectomy, it is important to recognize that most studies describe outcomes after surgery for cancer and not high-grade dysplasia, and that high-volume centers tend to have better outcomes. At high-volume centers with greater surgical expertise, the mortality rate from esophagectomy for cancer is $2 \%-3 \% .^{90,91}$ Furthermore, patients with cancers tend to be more debilitated preoperatively, and comorbid diseases are less frequent in patients with high-grade dysplasia alone. ${ }^{92}$ Esophagectomy performed specifically for high-grade dysplasia has a pooled mortality rate of $1 \%,{ }^{92}$ making it a lower-risk surgery than when performed for cancer. The best surgical option for high-grade dysplasia or intramucosal carcinoma should produce the least morbidity balanced against best long-term survival.

Several studies provide evidence that esophagectomy prevents cancer-related mortality in patients with high-grade dysplasia and intramucosal carcinoma. In a study at the Cleveland Clinic, pathologic review of resection specimens revealed high-grade dysplasia in 59 patients and invasive cancer in 50 patients. Operative mortality was $0 \%$, and 10 -year survival was $86 \%$ for both groups. ${ }^{93}$ Overall 5-year survival was $83 \%$ for all resected high-grade dysplasia patients $(91 \%$ for those without invasion and $68 \%$ for those with invasion). Operative mortality occurred in one patient (2\% mortality rate). ${ }^{94}$ Similar 5-year survival rates of $88 \%$ and $86 \%$ have been reported in similar studies. ${ }^{95,96}$

Recurrence rates of Barrett's esophagus or adenocarcinoma following esophagectomy have been assessed in a limited number of trials. In a study by Chang et al of 34 Barrett's esophagus patients with high-grade dysplasia or esophageal adenocarcinoma, the cure rate after esophagectomy and 2-year surveillance was $85 \%$, demonstrated by having no clinical, radiographic, or endoscopic evidence of recurrent esophageal adenocarcinoma or metastasis. ${ }^{97}$ In a study by Wolfsen et al the cure rate for dysplasia or localized esophageal adenocarcinoma was reported to be lower at $77.8 \%{ }^{98}$ This highlights the need for continued endoscopic surveillance following resection.

Conventional approaches for esophagectomy are transhiatal and transthoracic resection. Transhiatal resection without thoractomy can be done to prevent respiratory compromise, with the incidence of atelectasis or pneumonia being low $(2 \%$ and $<1 \%$ of cases, respectively). ${ }^{99} \mathrm{~A}$ randomized trial comparing 106 patients undergoing transhiatal esophagectomy and 114 patients undergoing transthoracic esophagectomy with lymphadenectomy demonstrated a significantly lower rate of postoperative respiratory complications with the transhiatal approach (27\% versus 57\%). A trend towards greater survival was shown for the transthoracic approach at 5 years (39\% versus 27\%). No significant difference was noted for inhospital mortality. ${ }^{100}$ One potential limitation of the transhiatal approach is the inability to retrieve lymph nodes required for nodal staging, ${ }^{101}$ more extensive resection using a transthoracic approach with thoracotomy likely improves staging accuracy. The needs of the patient (accurate staging versus functional status and operative risk) as well as the surgeon's expertise ultimately determine the preferred approach.

Minimally invasive esophagectomy utilizes video-assisted or laparoscopic techniques and is a promising approach. Minimally invasive esophagectomy has potential advantages over open esophagectomy because of a lower incidence of pulmonary complications, faster postoperative recovery, and decreased length of hospital stay. ${ }^{102}$ Minimally invasive esophagectomy avoids the thoracotomy and laparotomy, 
thus limiting the extent of surgical trauma and presumably reducing postoperative morbidity and increasing quality of life. ${ }^{103}$ However, lymph node retrieval is largely inferior to standards of open surgery, and morbidity and mortality of minimally invasive esophagectomy is not proven to be lower when compared with open esophagectomy at experienced centers. ${ }^{104}$ Recommendations favoring minimally invasive esophagectomy over open esophagectomy cannot be made due to a lack of randomized trials comparing the two approaches.

In patients with few comorbidities and an otherwise long life expectancy, a vagal-sparing esophagectomy can be considered to improve outcomes and quality of life. Peyre et al demonstrated lower infectious, respiratory, and anastomotic complications in patients with high-grade dysplasia or intramucosal carcinoma undergoing this procedure compared with transhiatal esophagectomy. Quality of life advantages were also demonstrated, with the potential for reduced morbidity owing to avoidance of postvagotomy dumping and diarrhea, as well as a shorter hospital stay. ${ }^{105}$ However, lymphadenectomy is not performed with this procedure, so it is not an option for patients with submucosal cancer given the need for nodal staging. Long-term outcomes data are lacking, thus its overall utility remains to be seen.

\section{Antireflux surgery}

Antireflux surgery using fundoplication theoretically eliminates acid reflux and provides better control of gastroesophageal reflux disease than PPIs. The concept that adequate reflux control following antireflux surgery is necessary to reduce the rate of progression of disease is supported by studies that suggest progression is significantly more likely to occur with a failed fundoplication and persistent reflux. ${ }^{4,106,107}$ In the only randomized trial to date comparing antireflux surgery and PPIs, 43 patients treated medically and 58 treated with antireflux surgery were compared. No significant difference between the two groups was found with respect to preventing progression to dysplasia and adenocarcinoma. ${ }^{108}$ Optimal candidates for antireflux surgery include those who lack major comorbidities and demonstrate some response to PPI therapy. ${ }^{33}$ Antireflux surgery has not been proven to reduce progression of nondysplastic Barrett's esophagus to high-grade dysplasia or adenocarcinoma significantly, and does not obviate the need for continued surveillance. The decision to pursue antireflux surgery should depend on patient preference and the severity of reflux symptoms despite PPI therapy, rather than for definitive management of intestinal metaplasia.

\section{Conclusion}

In summary, the management of Barrett's esophagus requires acid suppression and endoscopic assessment. For patients with nondysplastic Barrett's esophagus, treatment with a PPI may decrease acid exposure and delay the progression to dysplasia. A careful endoscopic examination should include assessment of any visible lesions in a Barrett's segment. An expert gastrointestinal pathologist should confirm neoplasia in the setting of Barrett's esophagus. For those patients with high-grade dysplasia or intramucosal carcinoma, careful consideration of endoscopic therapy or surgical therapy must be given. All visible lesions in the setting of dysplasia should be targeted with focal endoscopic mucosal resection for both accurate histopathologic diagnosis and for treatment. The remainder of the Barrett's epithelium should also be eradicated to address all synchronous and metachronous lesions. This may be done with tissue acquiring or nontissue acquiring means. Radiofrequency ablation has a positive benefit-risk profile for flat Barrett's esophagus. At this time, endoscopic therapy is not indicated for nondysplastic Barrett's esophagus. Esophagectomy is still reserved for selected cases with evidence of lymph node metastasis, unsuccessful endoscopic therapy, or with high-risk features of high-grade dysplasia or intramucosal carcinoma.

\section{Disclosure}

VJAK has received honoraria and consulting fees from Manua Kea Technologies, Paris, France.

\section{References}

1. Pohl H, Welch HG. The role of overdiagnosis and reclassification in the marked increase of esophageal adenocarcinoma incidence. J Natl Cancer Inst. 2005;97(2):142-146.

2. Enzinger PC, Mayer RJ. Esophageal cancer. $N$ Engl J Med. 2003; 349(23):2241-2252.

3. Fitzgerald RC, Lascar R, Triadafilopoulos G. Review article: Barrett's oesophagus, dysplasia and pharmacologic acid suppression. Aliment Pharmacol Ther. 2001;15(3):269-276.

4. Zehetner J, DeMeester SR, Ayazi S, et al. Long-term follow-up after anti-reflux surgery in patients with Barrett's esophagus. J Gastrointest Surg. 2010;14(10):1483-1491.

5. Cooper BT, Barbezat GO. Treatment of Barrett's esophagus with H2 blockers. J Clin Gastroenterol. 1987;9(2):139-141.

6. Neumann CS, Iqbal TH, Cooper BT. Long term continuous omeprazole treatment of patients with Barrett's oesophagus. Aliment Pharmacol Ther. 1995;9(4):451-454.

7. Peters FT, Ganesh S, Kuipers EJ, et al. Endoscopic regression of Barrett's oesophagus during omeprazole treatment; a randomised double blind study. Gut. 1999;45(4):489-494.

8. Gore S, Healey CJ, Sutton R, et al. Regression of columnar lined (Barrett's) oesophagus with continuous omeprazole therapy. Aliment Pharmacol Ther. 1993;7(6):623-628.

9. Sampliner RE. Effect of up to 3 years of high-dose lansoprazole on Barrett's esophagus. Am J Gastroenterol. 1994;89(10):1844-1848.

10. Cooper BT, Neumann CS, Cox MA, Iqbal TH. Continuous treatment with omeprazole $20 \mathrm{mg}$ daily for up to 6 years in Barrett's oesophagus. Aliment Pharmacol Ther. 1998;12(9):893-897. 
11. Wilkinson SP, Biddlestone L, Gore S, Shepherd NA. Regression of columnar-lined (Barrett's) oesophagus with omeprazole $40 \mathrm{mg}$ daily: Results of 5 years of continuous therapy. Aliment Pharmacol Ther. 1999;13(9):1205-1209.

12. Malesci A, Savarino V, Zentilin P, et al. Partial regression of Barrett's esophagus by long-term therapy with high-dose omeprazole. Gastrointest Endosc. 1996;44(6):700-705.

13. Cooper BT, Chapman W, Neumann CS, Gearty JC. Continuous treatment of Barrett's oesophagus patients with proton pump inhibitors up to 13 years: Observations on regression and cancer incidence. Aliment Pharmacol Ther. 2006;23(6):727-733.

14. Sharma P, Sampliner RE, Camargo E. Normalization of esophageal $\mathrm{pH}$ with high-dose proton pump inhibitor therapy does not result in regression of Barrett's esophagus. Am J Gastroenterol. 1997; 92(4):582-585.

15. Sampliner RE. Reduction of acid exposure and regression of Barrett's esophagus. Dig Dis. 2000;18(4):203-207.

16. Weston AP, Badr AS, Hassanein RS. Prospective multivariate analysis of factors predictive of complete regression of Barrett's esophagus. Am J Gastroenterol. 1999;94(12):3420-3426.

17. Gatenby PA, Ramus JR, Caygill CP, Charlett A, Winslet MC, Watson A. Treatment modality and risk of development of dysplasia and adenocarcinoma in columnar-lined esophagus. Dis Esophagus. 2009;22(2): $133-142$.

18. El-Serag HB, Aguirre TV, Davis S, Kuebeler M, Bhattacharyya A, Sampliner RE. Proton pump inhibitors are associated with reduced incidence of dysplasia in Barrett's esophagus. Am J Gastroenterol. 2004;99(10): 1877-1883.

19. Nguyen DM, El-Serag HB, Henderson L, Stein D, Bhattacharyya A, Sampliner RE. Medication usage and the risk of neoplasia in patients with Barrett's esophagus. Clin Gastroenterol Hepatol. 2009;7(12): 1299-1304.

20. Hillman LC, Chiragakis L, Shadbolt B, Kaye GL, Clarke AC. Proton-pump inhibitor therapy and the development of dysplasia in patients with Barrett's oesophagus. Med J Aust. 2004;180(8):387-391.

21. Heath CW Jr, Thun MJ, Greenberg ER, Levin B, Marnett LJ. Nonsteroidal antiinflammatory drugs and human cancer. Report of an interdisciplinary research workshop. Cancer. 1994;74(10):2885-2888.

22. Corley DA, Kerlikowske K, Verma R, Buffler P. Protective association of aspirin/NSAIDs and esophageal cancer: A systematic review and meta-analysis. Gastroenterology. 2003;124(1):47-56.

23. Fosslien E. Molecular pathology of cyclooxygenase-2 in neoplasia. Ann Clin Lab Sci. 2000;30(1):3-21.

24. Souza RF, Shewmake K, Beer DG, Cryer B, Spechler SJ. Selective inhibition of cyclooxygenase-2 suppresses growth and induces apoptosis in human esophageal adenocarcinoma cells. Cancer Res. 2000;60(20):5767-5772.

25. Morris CD, Armstrong GR, Bigley G, Green H, Attwood SE. Cyclooxygenase-2 expression in the Barrett's metaplasia-dysplasiaadenocarcinoma sequence. Am J Gastroenterol. 2001;96(4):990-996.

26. Buttar NS, Wang KK, Anderson MA, et al. The effect of selective cyclooxygenase-2 inhibition in Barrett's esophagus epithelium: An in vitro study. $J$ Natl Cancer Inst. 2002;94(6):422-429.

27. Vaughan TL, Dong LM, Blount PL, et al. Non-steroidal anti-inflammatory drugs and risk of neoplastic progression in Barrett's oesophagus: A prospective study. Lancet Oncol. 2005;6(12):945-952.

28. Anderson LA, Johnston BT, Watson RG, et al. Nonsteroidal antiinflammatory drugs and the esophageal inflammation-metaplasiaadenocarcinoma sequence. Cancer Res. 2006;66(9):4975-4982.

29. Nguyen DM, Richardson P, El-Serag HB. Medications (NSAIDs, statins, proton pump inhibitors) and the risk of esophageal adenocarcinoma in patients with Barrett's esophagus. Gastroenterology. 2010;138(7):2260-2266.

30. Spechler SJ, Sharma P, Souza RF, Inadomi JM, Shaheen NJ. American Gastroenterological Association medical position statement on the management of Barrett's esophagus. Gastroenterology. 2011;140(3): 1084-1091.
31. Henry D, Lim LL, Garcia Rodriguez LA, et al. Variability in risk of gastrointestinal complications with individual non-steroidal antiinflammatory drugs: Results of a collaborative meta-analysis. $B M J$. 1996;312(7046):1563-1566.

32. Heath EI, Canto MI, Piantadosi S, et al. Secondary chemoprevention of Barrett's esophagus with celecoxib: Results of a randomized trial. J Natl Cancer Inst. 2007;99(7):545-557.

33. Wang KK, Sampliner RE. Updated guidelines 2008 for the diagnosis, surveillance and therapy of Barrett's esophagus. Am J Gastroenterol. 2008;103(3):788-797.

34. Chennat JS, Konda VJ, Waxman I. Endotherapy for Barrett's esophagus: Which, how, when and who? Gastrointest Endosc Clin N Am. 2011;21(1):119-133.

35. Sharma P, Dent J, Armstrong D, et al. The development and validation of an endoscopic grading system for Barrett's esophagus: The Prague $\mathrm{C}$ and M criteria. Gastroenterology. 2006;131(5):1392-1399.

36. Mannath J, Subramanian V, Hawkey CJ, Ragunath K. Narrow band imaging for characterization of high grade dysplasia and specialized intestinal metaplasia in Barrett's esophagus: A meta-analysis. Endoscopy. 2010;42(5):351-359.

37. Curvers WL, Bohmer CJ, Mallant-Hent RC, et al. Mucosal morphology in Barrett's esophagus: Interobserver agreement and role of narrow band imaging. Endoscopy. 2008;40(10):799-805.

38. Kara MA, Peters FP, Ten Kate FJ, Van Deventer SJ, Fockens P, Bergman JJ. Endoscopic video autofluorescence imaging may improve the detection of early neoplasia in patients with Barrett's esophagus. Gastrointest Endosc. 2005;61(6):679-685.

39. Waxman I, Konda VJ. Endoscopic techniques for recognizing neoplasia in Barrett's esophagus: Which should the clinician use? Curr Opin Gastroenterol. 2010;26(4):352-360.

40. Dunbar KB, Okolo P 3rd, Montgomery E, Canto MI. Confocal laser endomicroscopy in Barrett's esophagus and endoscopically inapparent Barrett's neoplasia: A prospective, randomized, double-blind, controlled, crossover trial. Gastrointest Endosc. 2009;70(4):645-654.

41. Montgomery E, Bronner MP, Goldblum JR, et al. Reproducibility of the diagnosis of dysplasia in Barrett esophagus: A reaffirmation. Hum Pathol. 2001;32(4):368-378.

42. Ormsby AH, Petras RE, Henricks WH, et al. Observer variation in the diagnosis of superficial oesophageal adenocarcinoma. Gut. 2002;51(5):671-676.

43. Kerkhof M, van Dekken H, Steyerberg EW, et al. Grading of dysplasia in Barrett's oesophagus: Substantial interobserver variation between general and gastrointestinal pathologists. Histopathology. 2007;50(7):920-927.

44. Chennat J, Konda VJ, Ross AS, et al. Complete Barrett's eradication endoscopic mucosal resection: An effective treatment modality for high-grade dysplasia and intramucosal carcinoma - an American singlecenter experience. Am J Gastroenterol. 2009;104(11):2684-2692.

45. Wani S, Mathur SC, Curvers WL, et al. Greater interobserver agreement by endoscopic mucosal resection than biopsy samples in Barrett's dysplasia. Clin Gastroenterol Hepatol. 2010;8(9):783-788.

46. Ferguson MK, Naunheim KS. Resection for Barrett's mucosa with highgrade dysplasia: Implications for prophylactic photodynamic therapy. J Thorac Cardiovasc Surg. 1997;114(5):824-829.

47. Konda VJ, Ross AS, Ferguson MK, et al. Is the risk of concomitant invasive esophageal cancer in high-grade dysplasia in Barrett's esophagus overestimated? Clin Gastroenterol Hepatol. 2008;6(2): 159-164.

48. Paraf F, Flejou JF, Pignon JP, Fekete F, Potet F. Surgical pathology of adenocarcinoma arising in Barrett's esophagus. Analysis of 67 cases. Am J Surg Pathol. 1995;19(2):183-191.

49. Feith M, Stein HJ, Siewert JR. Pattern of lymphatic spread of Barrett's cancer. World J Surg. 2003;27(9):1052-1057.

50. Stein HJ, Feith M, Bruecher BL, Naehrig J, Sarbia M, Siewert JR. Early esophageal cancer: Pattern of lymphatic spread and prognostic factors for long-term survival after surgical resection. Ann Surg. 2005;242(4):566-573. 
51. Rice TW, Zuccaro G Jr, Adelstein DJ, Rybicki LA, Blackstone EH, Goldblum JR. Esophageal carcinoma: Depth of tumor invasion is predictive of regional lymph node status. Ann Thorac Surg. 1998;65(3):787-792.

52. Lopes CV, Hela M, Pesenti C, et al. Circumferential endoscopic resection of Barrett's esophagus with high-grade dysplasia or early adenocarcinoma. Surg Endosc. 2007;21(5):820-824.

53. van Sandick JW, van Lanschot JJ, ten Kate FJ, et al. Pathology of early invasive adenocarcinoma of the esophagus or esophagogastric junction: Implications for therapeutic decision making. Cancer. 2000;88(11):2429-2437.

54. Waxman I, Konda VJ. Mucosal ablation of Barrett esophagus. Nat Rev Gastroenterol Hepatol. 2009;6(7):393-401.

55. Ell C, May A, Gossner L, et al. Endoscopic mucosal resection of early cancer and high-grade dysplasia in Barrett's esophagus. Gastroenterology. 2000;118(4):670-677.

56. Larghi A, Lightdale CJ, Memeo L, Bhagat G, Okpara N, Rotterdam H. EUS followed by EMR for staging of high-grade dysplasia and early cancer in Barrett's esophagus. Gastrointest Endosc. 2005;62(1):16-23.

57. May A, Gossner L, Pech O, et al. Local endoscopic therapy for intraepithelial high-grade neoplasia and early adenocarcinoma in Barrett's oesophagus: Acute-phase and intermediate results of a new treatment approach. Eur J Gastroenterol Hepatol. 2002;14(10):1085-1091.

58. May A, Gossner L, Pech O, et al. Intraepithelial high-grade neoplasia and early adenocarcinoma in short-segment Barrett's esophagus (SSBE): Curative treatment using local endoscopic treatment techniques. Endoscopy. 2002;34(8):604-610.

59. Mino-Kenudson M, Brugge WR, Puricelli WP, et al. Management of superficial Barrett's epithelium-related neoplasms by endoscopic mucosal resection: Clinicopathologic analysis of 27 cases. Am J Surg Pathol. 2005;29(5):680-686.

60. Nijhawan PK, Wang KK. Endoscopic mucosal resection for lesions with endoscopic features suggestive of malignancy and high-grade dysplasia within Barrett's esophagus. Gastrointest Endosc. 2000;52(3):328-332.

61. Pech O, May A, Gossner L, Ell C. Barrett's esophagus: Endoscopic resection. Gastrointest Endosc Clin N Am. 2003;13(3):505-512.

62. Buttar NS, Wang KK, Sebo TJ, et al. Extent of high-grade dysplasia in Barrett's esophagus correlates with risk of adenocarcinoma. Gastroenterology. 2001;120(7):1630-1639.

63. Seewald S, Ang TL, Gotoda T, Soehendra N. Total endoscopic resection of Barrett esophagus. Endoscopy. 2008;40(12):1016-1020.

64. Pech O, Behrens A, May A, et al. Long-term results and risk factor analysis for recurrence after curative endoscopic therapy in 349 patients with high-grade intraepithelial neoplasia and mucosal adenocarcinoma in Barrett's oesophagus. Gut. 2008;57(9):1200-1206.

65. Peters FP, Kara MA, Rosmolen WD, et al. Stepwise radical endoscopic resection is effective for complete removal of Barrett's esophagus with early neoplasia: A prospective study. Am J Gastroenterol. 2006; 101(7):1449-1457.

66. Seewald S, Akaraviputh T, Seitz U, et al. Circumferential EMR and complete removal of Barrett's epithelium: A new approach to management of Barrett's esophagus containing high-grade intraepithelial neoplasia and intramucosal carcinoma. Gastrointest Endosc. 2003;57(7): 854-859.

67. Pouw RE, Seewald S, Gondrie JJ, et al. Stepwise radical endoscopic resection for eradication of Barrett's oesophagus with early neoplasia in a cohort of 169 patients. Gut. 2010;59(9):1169-1177.

68. Wang KK, Prasad G, Tian J. Endoscopic mucosal resection and endoscopic submucosal dissection in esophageal and gastric cancers. Curr Opin Gastroenterol. 2010;26(5):453-458.

69. Yoshinaga S, Gotoda T, Kusano C, Oda I, Nakamura K, Takayanagi R. Clinical impact of endoscopic submucosal dissection for superficial adenocarcinoma located at the esophagogastric junction. Gastrointest Endosc. 2008;67(2):202-209.

70. van Vilsteren FG, Pouw RE, Seewald S, et al. Stepwise radical endoscopic resection versus radiofrequency ablation for Barrett's oesophagus with high-grade dysplasia or early cancer: a multicentre randomised trial. Gut. 2011;60(6):765-773.
71. Sharma VK, Wang KK, Overholt BF, et al. Balloon-based, circumferential, endoscopic radiofrequency ablation of Barrett's esophagus: 1-year follow-up of 100 patients. Gastrointest Endosc. 2007;65(2):185-195.

72. Fleischer DE, Overholt BF, Sharma VK, et al. Endoscopic ablation of Barrett's esophagus: A multicenter study with 2.5-year follow-up. Gastrointest Endosc. 2008;68(5):867-876.

73. Fleischer DE, Overholt BF, Sharma VK, et al. Endoscopic radiofrequency ablation for Barrett's esophagus: 5-year outcomes from a prospective multicenter trial. Endoscopy. 2010;42(10):781-789.

74. Shaheen NJ, Sharma P, Overholt BF, et al. Radiofrequency ablation in Barrett's esophagus with dysplasia. N Engl J Med. 2009; 360(22):2277-2288.

75. Ganz RA, Overholt BF, Sharma VK, et al. Circumferential ablation of Barrett's esophagus that contains high-grade dysplasia: A US Multicenter Registry. Gastrointest Endosc. 2008;68(1):35-40.

76. Pouw RE, Wirths K, Eisendrath P, et al. Efficacy of radiofrequency ablation combined with endoscopic resection for Barrett's esophagus with early neoplasia. Clin Gastroenterol Hepatol. 2010;8(1):23-29.

77. Gross SA, Wolfsen HC. The role of photodynamic therapy in the esophagus. Gastrointest Endosc Clin N Am. 2010;20(1):35-53, vi.

78. Overholt BF, Panjehpour M, Halberg DL. Photodynamic therapy for Barrett's esophagus with dysplasia and/or early stage carcinoma: Long-term results. Gastrointest Endosc. 2003;58(2):183-188.

79. Pech O, Gossner L, May A, et al. Long-term results of photodynamic therapy with 5-aminolevulinic acid for superficial Barrett's cancer and high-grade intraepithelial neoplasia. Gastrointest Endosc. 2005;62(1):24-30

80. Prasad GA, Wang KK, Buttar NS, Wongkeesong LM, Lutzke LS, Borkenhagen LS. Predictors of stricture formation after photodynamic therapy for high-grade dysplasia in Barrett's esophagus. Gastrointest Endosc. 2007;65(1):60-66.

81. Van Laethem JL, Peny MO, Salmon I, Cremer M, Deviere J. Intramucosal adenocarcinoma arising under squamous re-epithelialisation of Barrett's oesophagus. Gut. 2000;46(4):574-577.

82. Kuflik EG. Cryosurgery updated. J Am Acad Dermatol. 1994;31(6) 925-944.

83. Dumot JA, Vargo JJ 2nd, Falk GW, Frey L, Lopez R, Rice TW. An openlabel, prospective trial of cryospray ablation for Barrett's esophagus high-grade dysplasia and early esophageal cancer in high-risk patients. Gastrointest Endosc. 2009;70(4):635-644.

84. Greenwald BD, Dumot JA, Horwhat JD, Lightdale CJ, Abrams JA. Safety, tolerability, and efficacy of endoscopic low-pressure liquid nitrogen spray cryotherapy in the esophagus. Dis Esophagus. 2010; 23(1):13-19.

85. Shaheen NJ, Greenwald BD, Peery AF, et al. Safety and efficacy of endoscopic spray cryotherapy for Barrett's esophagus with high-grade dysplasia. Gastrointest Endosc. 2010;71(4):680-685.

86. Shaheen NJ, Peery AF, Overholt BF, et al. Biopsy depth after radiofrequency ablation of dysplastic Barrett's esophagus. Gastrointest Endosc. 2010;72(3):490e1-496e1.

87. Bozio G, Baulieux J, Mabrut JY. The role of surgery in the management of Barrett's esophagus (from dysplasia to cancer). J Visc Surg. 2011;148(1):19-26.

88. Konda VJ, Ferguson MK. Esophageal resection for high-grade dysplasia and intramucosal carcinoma: When and how? World J Gastroenterol. 2010;16(30):3786-3792.

89. Bailey SH, Bull DA, Harpole DH, et al. Outcomes after esophagectomy: A ten-year prospective cohort. Ann Thorac Surg. 2003;75(1):217-222.

90. Birkmeyer JD, Stukel TA, Siewers AE, Goodney PP, Wennberg DE, Lucas FL. Surgeon volume and operative mortality in the United States. N Engl J Med. 2003;349(22):2117-2127.

91. Law S. Esophagectomy without mortality: What can surgeons do? J Gastrointest Surg. 2010;14 Suppl 1:S101-S107.

92. Fernando HC, Murthy SC, Hofstetter W, et al. The Society of Thoracic Surgeons practice guideline series: Guidelines for the management of Barrett's esophagus with high-grade dysplasia. Ann Thorac Surg. 2009;87(6):1993-2002. 
93. Rice TW. Pro: Esophagectomy is the treatment of choice for high-grade dysplasia in Barrett's esophagus. Am J Gastroenterol. 2006;101(10):2177-2179.

94. Reed MF, Tolis G Jr, Edil BH, et al. Surgical treatment of esophageal high-grade dysplasia. Ann Thorac Surg. 2005;79(4):1110-1115.

95. Tseng EE, Wu TT, Yeo CJ, Heitmiller RF. Barrett's esophagus with high grade dysplasia: Surgical results and long-term outcome - an update. J Gastrointest Surg. 2003;7(2):164-170.

96. Headrick JR, Nichols FC 3rd, Miller DL, et al. High-grade esophageal dysplasia: Long-term survival and quality of life after esophagectomy. Ann Thorac Surg. 2002;73(6):1697-1702.

97. Chang LC, Oelschlager BK, Quiroga E, et al. Long-term outcome of esophagectomy for high-grade dysplasia or cancer found during surveillance for Barrett's esophagus. J Gastrointest Surg. 2006; 10(3):341-346.

98. Wolfsen HC, Hemminger LL, DeVault KR. Recurrent Barrett's esophagus and adenocarcinoma after esophagectomy. BMC Gastroenterol. 2004; $4: 18$

99. Orringer MB, Marshall B, Iannettoni MD. Transhiatal esophagectomy: Clinical experience and refinements. Ann Surg. 1999;230(3): 392-400.

100. Hulscher JB, van Sandick JW, de Boer AG, et al. Extended transthoracic resection compared with limited transhiatal resection for adenocarcinoma of the esophagus. N Engl J Med. 2002;347(21):1662-1669.

101. Wolff CS, Castillo SF, Larson DR, et al. Ivor Lewis approach is superior to transhiatal approach in retrieval of lymph nodes at esophagectomy. Dis Esophagus. 2008;21(4):328-333.
102. Biere SS, Cuesta MA, van der Peet DL. Minimally invasive versus open esophagectomy for cancer: A systematic review and metaanalysis. Minerva Chir. 2009;64(2):121-133.

103. Biere SS, Maas KW, Bonavina L, et al. Traditional invasive vs minimally invasive esophagectomy: a multi-center, randomized trial (TIME-trial). BMC Surg. 2011;11:2.

104. Decker G, Coosemans W, De Leyn P, et al. Minimally invasive esophagectomy for cancer. Eur J Cardiothorac Surg. 2009;35(1): 13-20.

105. Peyre CG, DeMeester SR, Rizzetto C, et al. Vagal-sparing esophagectomy: The ideal operation for intramucosal adenocarcinoma and Barrett with high-grade dysplasia. Ann Surg. 2007;246(4): 665-671.

106. Lagergren J, Viklund P. Is esophageal adenocarcinoma occurring late after antireflux surgery due to persistent postoperative reflux? World J Surg. 2007;31(3):465-469.

107. O'Riordan JM, Byrne PJ, Ravi N, Keeling PW, Reynolds JV. Long-term clinical and pathologic response of Barrett's esophagus after antireflux surgery. Am J Surg. 2004;188(1):27-33.

108. Parrilla P, Martinez de Haro LF, et al. Long-term results of a randomized prospective study comparing medical and surgical treatment of Barrett's esophagus. Ann Surg. 2003;237(3):291-298.
Therapeutics and Clinical Risk Management

\section{Publish your work in this journal}

Therapeutics and Clinical Risk Management is an international, peerreviewed journal of clinical therapeutics and risk management, focusing on concise rapid reporting of clinical studies in all therapeutic areas, outcomes, safety, and programs for the effective, safe, and sustained use of medicines. This journal is indexed on PubMed Central, CAS,

\section{Dovepress}

EMBase, Scopus and the Elsevier Bibliographic databases. The manuscript management system is completely online and includes a very quick and fair peer-review system, which is all easy to use. Visit $\mathrm{http}: / / \mathrm{www}$.dovepress.com/testimonials.php to read real quotes from published authors. 